\title{
Development and use of the Wetland Fish Index to assess the quality of coastal wetlands in the Laurentian Great Lakes
}

\author{
T.S. Seilheimer and P. Chow-Fraser
}

\begin{abstract}
We use fish and environmental data from 40 wetlands of the Laurentian Great Lakes to develop the Wetland Fish Index (WFI), a tool that can be used to assess the quality of coastal marshes. A partial canonical correspondence analysis was used to ordinate fish species along multidimensional environmental axes that accounted for anthropogenic disturbance based on temperature, conductivity, and the presence of pollutants (e.g., suspended solids and primary nutrients). Compared with other measures of fish habitat quality (e.g., Shannon-Wiener diversity index and species richness), the WFI was the only index that was significantly related to the degree of water quality degradation and wetlands condition, as indicated by an independent index of wetland quality, the Water Quality Index (WQI). WQI ranks sites according to deterioration in water quality and is statistically related to the degree of land-use alteration in wetland watersheds. We demonstrate the usefulness of the WFI for detecting intrawetland variation between two sites in a degraded urban wetland, Frenchman's Bay, Lake Ontario, and to distinguish the heavily impacted wetlands in lower Green Bay from the less-impacted marshes in middle and upper Green Bay, Lake Michigan. This was accomplished by using only published fish data without corresponding environmental variables.
\end{abstract}

\begin{abstract}
Résumé : Nous avons utilisé des données sur les poissons et sur le milieu provenant de 40 terres humides des Grands Lacs laurentiens afin de mettre au point un indice ichtyologique des terres humides (WFI, Wetland Fish Index), un outil qui peut permettre d'évaluer la qualité des marais côtiers. Une analyse partielle des correspondances canoniques a servi à ordonner les espèces de poissons le long d'axes environnementaux multidimensionnels qui expliquent les perturbations anthropiques d'après la température, la conductivité et la présence de polluants (par exemple, de solides en suspension et de nutriments primaires). Par comparaison à d'autres mesures de la qualité de l'habitat des poissons (par exemple, l'indice de diversité de Shannon-Wiener et la richesse spécifique), le WFI est le seul qui soit relié significativement à l'importance de la dégradation de la qualité de l'eau et à l'état des terres humides, tel qu'indiqué par un indice indépendant de la qualité des terres humides, l'indice de qualité de l'eau (WQI, Water Quality Index). Le WQI ordonne les sites d'après la détérioration de la qualité de leur eau et montre une corrélation significative avec les modifications associées à l'utilisation des terres dans le bassin versant des terres humides. Nous montrons l'utilité de WFI pour détecter la variation dans un même système entre deux sites dans Frenchman's Bay, lac Ontario, une terre humide urbaine et dégradée; il peut aussi distinguer les terres humides fortement modifiées de la partie inférieure de Green Bay. lac Michigan, des régions moins affectées des parties moyennes et supérieures de la baie. Cela a pu être réalisé à partir seulement des données publiées sur les poissons, sans utiliser les variables environnementales correspondantes.
\end{abstract}

[Traduit par la Rédaction]

\section{Introduction}

Coastal wetlands of the Great Lakes exist at the interface between the terrestrial and aquatic ecosystems. Hydrologically connected either seasonally or permanently, these shallow marshes have diverse emergent and submergent vegetation that provide important spawning habitat for many species of the Great Lakes fish community (Jude and Pappas 1992).

Received 22 November 2004. Accepted 14 July 2005.

Published on the NRC Research Press Web site at

http://cjfas.nrc.ca on 11 January 2006.

J18416

T.S. Seilheimer ${ }^{1}$ and P. Chow-Fraser. McMaster University, Biology Department, 1280 Main Street West, Hamilton, ON L8S 4K1, Canada.

${ }^{1}$ Corresponding author (e-mail: seilhets@mcmaster.ca).
There is well-documented evidence that land-use alteration in the watersheds of coastal wetlands can negatively affect their habitat quality (Crosbie and Chow-Fraser 1999; Lougheed et al. 2001; Chow-Fraser 2006). Agricultural and urban development is generally accompanied by a high nutrient and sediment load to the wetlands, leading to high algal production and increased water turbidity. These changes can cause an overall decrease in macrophyte abundance and diversity (Chow-Fraser et al. 1998). Submergent vegetation is crucial for piscivores (e.g., largemouth bass, Micropterus salmoides; northern pike, Esox lucius) and forage species (e.g., yellow perch, Perca flavescens; sunfish, Lepomis sp.; and cyprinids) because it provides structure for spawning, refugia for larvae and juveniles, and habitat for benthic and planktonic prey (Casselman and Lewis 1996). The plants can also provide shade, reducing local temperature and making it suitable for many cool-water species (Wichert and Lin 1996). Any anthropogenic factor that degrades the overall 
habitat quality in coastal wetlands can cause a shift in the fishes toward more pollution-tolerant and less desirable assemblages (Brazner and Beals 1997).

A common goal of fish managers is to track available habitat by using appropriate assessment tools to determine the overall quality of particular wetlands. A number of biological indicators have recently been developed for coastal wetlands and littoral habitats of the Great Lakes that involve the use of periphytic algae (McNair and Chow-Fraser 2003), benthic invertebrates (Wilcox et al. 2002; Weigel 2003), the fish community (Minns et al. 1994), and water quality information (Chow-Fraser 2006). Of these, indicators involving fish are advantageous because they involve multiple trophic levels, require less total processing time, and yield results that can be easily interpreted by the general public (Karr 1981). The relationship between fish and anthropogenic degradation is the basis for fish indices of habitat condition due to the tolerance and intolerance of certain species and groups of species (e.g., number of tolerant species metrics).

There are three main objectives in this study. First, we will develop the Wetland Fish Index (WFI) to assess the degree of human impact on the quality of coastal wetlands. An implicit assumption is that wetlands can be ranked according to the degree of anthropogenic disturbance, as indicated by water quality deterioration (i.e., increased nutrient concentrations; water turbidity, temperature, and conductivity; etc. (Chow-Fraser et al. 1998; Crosbie and Chow-Fraser 1999). Further, we assume that this degradation will be reflected in the species composition of the fish community, in a manner similar to that described in Lougheed and Chow-Fraser (2002) for zooplankton (Wetland Zooplankton Index). In developing this index, we will explore how the fish community reflects known environmental degradation. A second objective is to compare the utility of the WFI with other published indices of habitat quality, including the Water Quality Index (WQI; Chow-Fraser 2006), the near-shore fish Index of Biotic Integrity (IBI) developed by Minns et al. (1994), and Weighted Species-Association Tolerance indices for Water Quality (WSATI-WQ) and Water Temperature (WSATI-WT; Wichert and Lin 1996). Third, we use fishassemblage information to generate WFI scores for two sites in Frenchman's Bay, a highly urbanized wetland of Lake Ontario that has degraded water-quality conditions in the north end because of runoff from a major provincial highway and measurably better water quality in the south end because of constant mixing with Lake Ontario water. We will also use published literature to validate the usefulness of the WFI for assessing the quality of 12 coastal wetlands and 12 beaches in Green Bay, Lake Michigan, which are located in a region outside the area sampled for development of the index (Brazner and Beals 1997).

\section{Materials and methods}

\section{Study sites}

In this study, we collected fish and environmental data from 40 wetlands located along the shoreline of four of the Great Lakes (Fig. 1). Because of the large latitudinal gradient in our data set, there are large differences in degree-days and wetland geomorphology that may confound any effect of human disturbance on the quality of fish habitat in wet- lands. To reduce the effect of the large latitudinal gradient, we selected sites in similar ecoregions (Fuller et al. 1995) that occurred primarily along the shoreline of Lake Ontario, Lake Erie - Niagara River, Lake Michigan, and Saginaw Bay, Lake Huron. During the development of the index, we found that upper and lower lakes could not be combined because of the differences in fish assemblage due to climate.

Two sites in the Great Lakes will be used to demonstrate the use of the WFI: Frenchman's Bay and Green Bay. Frenchman's Bay is a semi-enclosed, lagoon-type wetland located in the city of Pickering, Ontario (Fig. 1, inset $a$ ). The watershed covers an area of over $20 \mathrm{~km}^{2}$, of which more than $80 \%$ is urbanized (Eyles et al. 2003). From largest to smallest drainage area, the four main tributaries in the watershed are Krosno, Pine, Amberlea, and Dunbarton. Frenchman's Bay has a total area of 85 ha, 47 ha of which is open water (Environment Canada 2001), with a maximum depth of $3.5 \mathrm{~m}$ in midsummer. Green Bay is a $193 \mathrm{~km}$ long, shallow bay in northeastern Lake Michigan (Fig. 1, inset $b$ ). For present purposes, it is divided into areas based on regional differences in watersheds and water quality identified by Brazner and Beals (1997).

\section{Description of the database for development of WFI}

We conducted a field survey of 40 wetlands over three sampling seasons beginning the summer of 2000; one wetland was visited in two consecutive seasons during the period from mid-June to mid-August for a total of 41 fishing days (Table 1; Fig. 1). These wetlands were selected from established "eco-reaches" along the shoreline of four Great Lakes (after Chow-Fraser and Albert 1998; Wei et al. 2004). The sites were found in similar "ecoregions" (Fuller et al. 1995; Bailey 1995), based on climatic, vegetative, and geological conditions. Sites were selected along a wide gradient of habitat and water-quality degradation, based on a parallel monitoring program of environmental variables, including macrophyte abundance and diversity (Lougheed et al. 2001; McNair and Chow-Fraser 2003).

\section{Field sampling}

For each wetland, we measured a set of important variables for fish habitat, which included water-quality parameters, substrate type, and other physical attributes. Wetlands were visited between early June and late August during 2000-2002 inclusive. Water samples were collected from an open water site located at least $10 \mathrm{~m}$ from the edge of the emergent aquatic vegetation for analysis of planktonic algae, primary nutrients, and suspended solids; in certain wetlands, submergent vegetation was present throughout, and in those cases we sampled in the deeper areas that had very little submergent vegetation. This minimized contaminating the samples with benthic algae (either epiphytic or periphytic). Water samples were collected with a 1 L Van Dorn bottle deployed at mid-depth and dispensed into clean Nalgene bottles (acid-washed and rinsed with deionized water) for nutrient analyses. Samples for chlorophyll analyses were stored in opaque Nalgene bottles. All samples were kept in sample jars and frozen until analysis (usually within 3 months of collection).

Temperature, conductivity (COND), dissolved oxygen, and turbidity were measured $10 \mathrm{~m}$ from the submergent vegeta- 
Fig. 1. Location of study sites (circles) around the shoreline of the Great Lakes used in the development of the Wetland Fish Index, with map of Frenchman's Bay marsh and location of the sampling sites (inset $a$ ) and location of Green Bay in Lake Michigan with regions from Brazner and Beals (1997; inset $b$ ).

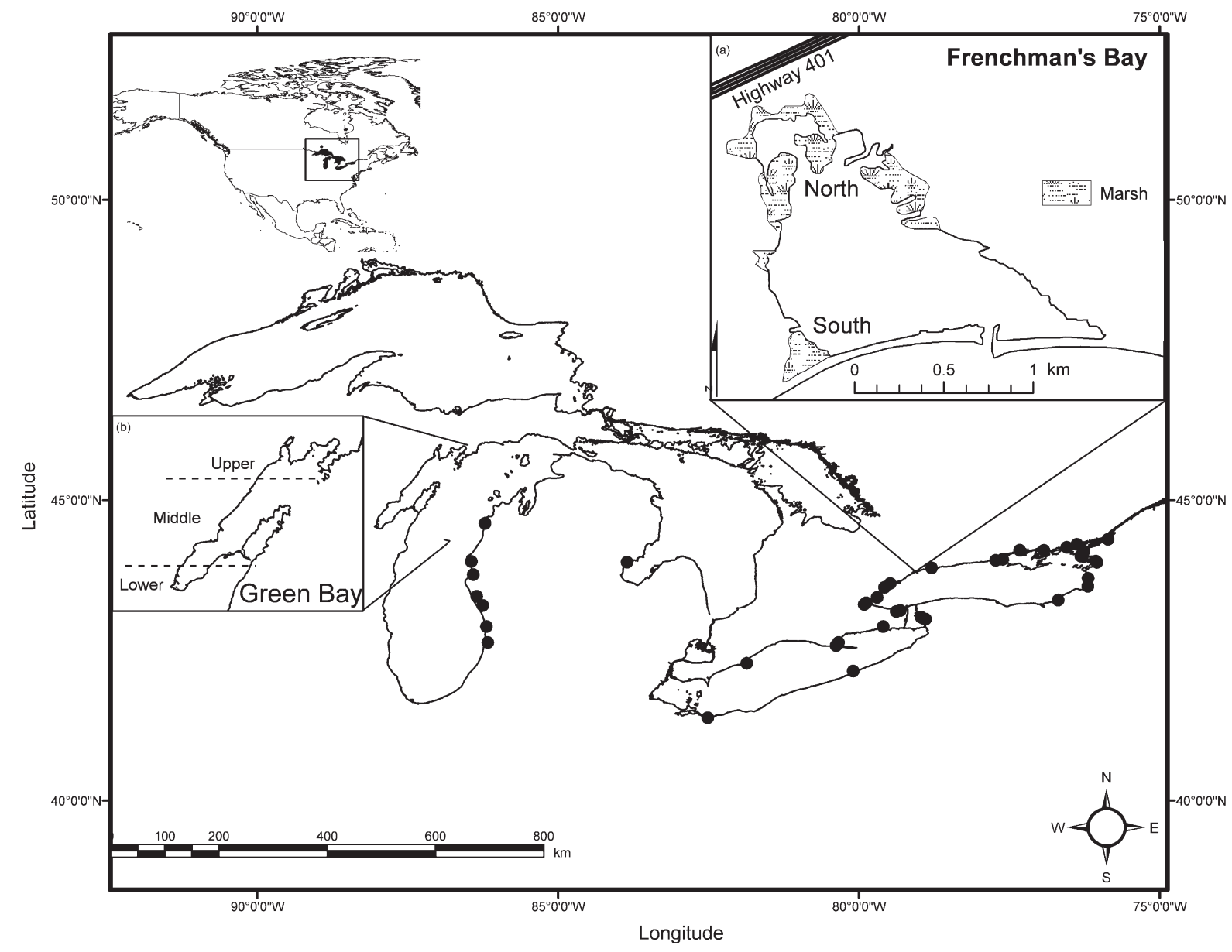

tion with a Hydrolab Minisonde multiparameter probe attached to a Surveyor display (Hydrolab, Austin, Texas) during 2000-2001. A YSI 6600 multiparameter probe with two optical sensors (turbidity and chlorophyll) and a YSI 650 display (YSI, Yellow Springs, Ohio) was used in 2002. At the end of the 2001 field season, we conducted a side-byside comparison of both the Hydrolab Minisonde and YSI 6600 , and found no significant $(P>0.05)$ deviations with respect to any of the parameters, except for turbidity. We therefore chose to use the YSI 6600 for routine monitoring in 2002 because it was much easier to use. However, to ensure valid comparisons, turbidity data were not used in statistical analyses between years. Instead, we used the Hach 2100 Portalab (Hach, Loveland, Colorado) to measure turbidities in triplicate from water samples collected with the Van Dorn sampler. All sites were georeferenced with a handheld global positioning system unit (4-6 m accuracy).

To survey the fish community, we used three pairs of fyke nets (two pairs of large nets (13 and $4 \mathrm{~mm}$ bar mesh, $4.25 \mathrm{~m}$ length, $1 \mathrm{~m} \times 1.25 \mathrm{~m}$ front opening) and one pair of small nets $(4 \mathrm{~mm}$ bar mesh, $2.1 \mathrm{~m}$ length, $0.5 \mathrm{~m} \times 1.0 \mathrm{~m}$ front opening)) that were set parallel to the emergent zone at the 1 and $0.5 \mathrm{~m}$ depth contour, respectively. The paired nets were positioned face-to-face with a $7 \mathrm{~m}$ lead connecting them, while $2.5 \mathrm{~m}$ wings were set off the front openings at a $45^{\circ}$ angle. Whenever possible, nets were set within submergent vegetation, but when there was too little vegetation or when appropriate depths were not available, the nets were set near the emergent vegetation. After $24 \mathrm{~h}$, fish present in the nets were sized, enumerated, and identified according to Scott and Crossman (1998). Unknown species (i.e., small cyprinids) were frozen and identified later with a dissecting microscope. All other individuals were released live at the site. Fish data were pooled for the three nets at each wetland.

On nine different occasions from November 2001 to October 2002, we conducted fish surveys at the North and South sites in Frenchman's Bay, Lake Ontario (see Fig. 1, inset $a$ ). Because of the small size of the bay, we used only one pair of large nets at each site. An intensive water-quality monitoring program was carried out from May to September in 2002 at both sites, as well as an open-water area; on an approximately biweekly basis, water samples were collected for nutrients, chlorophyll $a$, and suspended solids as mentioned above. Two YSI 6600 multiparameter probes were also deployed in the North and South sites (see locations in Fig. 1, inset $a$ ) to take hourly measurements of temperature, $\mathrm{pH}$, conductivity, dissolved oxygen, turbidity, and chloro- 
Table 1. Summary of wetland locations, coordinates (decimal degrees), year sampled, and Water Quality Index (WQI) scores.

\begin{tabular}{|c|c|c|c|c|c|}
\hline Great Lake & Wetland & Latitude $\left({ }^{\circ} \mathrm{N}\right)$ & Longitude $\left({ }^{\circ} \mathrm{W}\right)$ & Year sampled & WQI* \\
\hline \multirow[t]{8}{*}{ Erie-Niagara } & Buckhorn & 43.0563 & 78.9712 & 2001 & -0.70 \\
\hline & Grand River & 42.9000 & 79.6000 & 2001 & -1.73 \\
\hline & Long Point & 42.5893 & 80.3355 & 2001 & 0.76 \\
\hline & Old Woman Creek & 41.3822 & 82.5145 & 2002 & -2.39 \\
\hline & Presque Isle & 42.1590 & 80.0985 & 2001 & -0.04 \\
\hline & Rondeau Bay & 42.2880 & 81.8670 & 2001 & 0.52 \\
\hline & Spicer Creek & 43.0234 & 78.8968 & 2001 & 1.51 \\
\hline & Turkey Point & 42.6336 & 80.3417 & 2002 & 0.77 \\
\hline Huron & Wigwam Bay & 43.9702 & 83.8543 & 2001 & 0.43 \\
\hline \multirow[t]{8}{*}{ Michigan } & Betsie & 44.6129 & 86.2142 & 2001 & -0.10 \\
\hline & Kalamazoo & 42.6335 & 86.1668 & 2001 & -1.18 \\
\hline & Lincoln & 43.9800 & 86.4400 & 2001 & -0.54 \\
\hline & Manistee River & 44.2622 & 86.2958 & 2001 & -0.33 \\
\hline & Muskegon & 43.2501 & 86.2501 & 2001 & 0.24 \\
\hline & Pentwater & 43.7628 & 86.4078 & 2001 & -0.72 \\
\hline & Pigeon River & 42.8997 & 86.1883 & 2001 & -0.09 \\
\hline & White River & 43.4002 & 86.3500 & 2001 & 0.24 \\
\hline \multirow[t]{24}{*}{ Ontario } & Blessington Bay & 44.1670 & 77.3330 & 2001 & 0.30 \\
\hline & Bronte Creek & 43.3833 & 79.7002 & 2002 & -0.89 \\
\hline & Cootes Paradise & 43.2667 & 79.9167 & 2001 & -1.46 \\
\hline & Cootes Paradise & 43.2667 & 79.9167 & 2002 & -1.02 \\
\hline & Credit River & 43.5500 & 79.5800 & 2002 & -1.50 \\
\hline & Darlington & 43.8730 & 78.7970 & 2002 & -0.68 \\
\hline & Fifteen Mile Creek & 43.1669 & 79.3167 & 2002 & -1.86 \\
\hline & Goose Bay & 44.3501 & 75.8667 & 2002 & -0.05 \\
\hline & Grass Bay & 44.1502 & 76.2668 & 2002 & 1.17 \\
\hline & Grindstone Creek & 43.2932 & 79.8839 & 2002 & -1.22 \\
\hline & Grindstone Sunfish Pond & 43.2833 & 79.8833 & 2002 & -2.01 \\
\hline & Hay Bay Marsh & 44.1667 & 76.9334 & 2002 & 0.07 \\
\hline & Humber River & 43.6167 & 79.4833 & 2002 & -1.20 \\
\hline & Jordan Harbour & 43.1501 & 79.3833 & 2002 & -1.05 \\
\hline & Little Cataraqui Creek & 44.2167 & 76.5500 & 2002 & -1.15 \\
\hline & Little Sodus & 43.3394 & 76.6945 & 2001 & 0.42 \\
\hline & Madoma Creek & 44.2667 & 76.3833 & 2002 & 0.63 \\
\hline & Mud Bay & 44.0668 & 76.3167 & 2002 & -0.49 \\
\hline & Muskellunge River & 43.9668 & 76.0501 & 2002 & -0.10 \\
\hline & Perch River & 43.9836 & 76.0669 & 2002 & 0.16 \\
\hline & Presqu'ile Provincial Park & 44.0000 & 77.7306 & 2002 & 0.57 \\
\hline & Salmon River & 43.5683 & 76.2022 & 2002 & 1.43 \\
\hline & Sandy Creek & 43.7009 & 76.1965 & 2001 & 1.23 \\
\hline & Wellers Bay & 44.0168 & 77.6167 & 2002 & 1.23 \\
\hline
\end{tabular}

*WQI categories: -3 to -2 , highly degraded; -2 to -1 , very degraded; -1 to 0 , moderately degraded; 0 to 1 , good; 1 to 2 , very good; 2 to 3 , excellent.

phyll $a$. All laboratory methods used to process waterquality samples have been detailed elsewhere (Lougheed et al. 1998; Chow-Fraser 1999, 2006).

\section{Published data for validation}

Published data in the appendix of Brazner and Beals (1997) were used to validate the WFI. In 1990 and 1991, Brazner (1997) used a combination of fyke nets, trap nets, and bag seines to survey the fish community of 24 wetland and beach habitats in Green Bay, Lake Michigan. The sampling sites were divided among three regions of Green Bay: lower, middle, and upper bay (see Fig. 1, inset $b$ ). The least- impacted areas were primarily located in upper bay, while the heavily impacted areas were located in lower bay, as indicated by distance from cities and highways and by a relative index of development.

\section{Statistical analyses}

CANOCO 4.5 (ter Braak and Smilauer 1998) was used to run canonical correspondence analysis (CCA). Fish species and wetlands were ordinated by creating synthetic axes that best fit the gradients of the environmental data (ter Braak and Verdonschot 1995). Prior to conducting the CCA, we used the detrended correspondence analysis (DCA) to verify 
that the species had a unimodal distribution over the environmental gradient (i.e., length of the gradient was greater than 4.0 standard deviation units; ter Braak and Smilauer 1998). All environmental variables and species abundances (pooled data from three fyke nets) were $\log _{10}$-transformed and standardized to have zero mean and unit variance. Rare species (i.e., those occurring in only one wetland) were excluded from this analysis to allow for the index to focus on the more common species that are more likely to be encountered by other investigators. We used Monte Carlo permutations under the full model (500 random permutations; ter Braak and Smilauer 1998) to determine the statistical significance of the canonical axes and analyzed presence or absence (PA) and abundance (AB) data separately. To adjust for seasonal variation in the data set, a partial CCA (pCCA) was used, rather than a regular CCA, with day of the year as a covariable (ter Braak and Verdonschot 1995). ShannonWiener diversity and Simpson's evenness values were calculated with MVSP (version 3.1, Kovach Computing Services, Ithaca, New York). All other statistical analyses were preformed using SAS JMP IN (version 5.1, SAS Institute Inc., Cary, North Carolina).

\section{Development of the WFI}

We used observed trends in the pCCA to guide the development of the WFI. Because the first axis appeared to ordinate wetlands according to degree of water-quality degradation, we used pCCA axis 1 to derive values for optimum and tolerance (hereafter referred to as $U$ and $T$, respectively; ter Braak and Verdonschot 1995). A centroid is the center of a cluster of species scores, and we used the placement of this centroid along the synthetic degradation axis to indicate the species' $U$ value. Each species was assigned a weight that corresponded to its position on pCCA axis 1 , where 1 indicated most tolerant to degradation and 5 was most intolerant to degradation. The weighted standard deviations of the species scores on pCCA axis 1 were used to indicate niche breadth and were used to assign the $T$ values, where 1 indicated a wide niche breadth and 3 indicated a narrow niche breadth. Species having narrow niche breadths were indicative of specific environmental conditions and were more useful as indicator species. Species occurring in 5\% or fewer wetlands were given a $T$ value of 1 , since we do not know if those taxa truly have a narrow niche or if the fishing method we used was ineffective in sampling those species.

To develop the WFI, each species was assigned $U$ and $T$ values according to the following equation (Kelly and Whitton 1995; Lougheed and Chow-Fraser 2002):

$$
\mathrm{WFI}=\frac{\sum_{i=1}^{n} Y_{i} T_{i} U_{i}}{\sum_{i=1}^{n} Y_{i} T_{i}}
$$

where $Y_{i}$ is the presence or $\log _{10}$ abundance $(\log (x+1))$ of species $i, T_{i}$ is the value from 1 to 3 (indicating niche breadth), and $U_{i}$ is the value from 1 to 5 (indicating tolerance of degradation). WFI (PA) refers to scores calculated using presence or absence data, and WFI (AB) refers to scores when $\log _{10}$ abundance $(\log (x+1))$ data was used. WQI scores corresponding to each wetland in this study were obtained from Chow-Fraser (2006), an independently derived index based on only water-quality data collected from 110 wetlands located throughout the five Great Lakes. This index ranges from -3 , which is indicative of the most impacted conditions, to +3 , which is indicative of the most undisturbed sites. An appropriate 12-variable equation from Chow-Fraser (2006) was used to calculate WQI scores for all wetlands in the study using data collected at the same time as the fish collection and the two long-term stations in Frenchman's Bay.

For examples of WFI use, we compared WFI scores between two sites of Frenchman's Bay that differed with respect to the level of urban impact. We also used the fish information from Frenchman's Bay to calculate corresponding fish IBI scores (Minns et al. 1994). Although their IBI was developed for Areas of Concern (AOC) littoral zones, Frenchman's Bay is adjacent to the Toronto AOC and has similar impacts. They also used $100 \mathrm{~m}$ electrofishing transects to derive their IBI, while we used fyke nets, but the sampling effort was consistent between study sites; hence any bias due to gear type would be constant for within-study comparisons. We also calculated the WSATI-WQ and WSATI-WT (Wichert and Lin 1996) for the two sites. Although these indices were developed for species occurring in streams rather than in wetlands, many of the species used in developing the indices occur in Frenchman's Bay, and on that basis, we felt they were appropriate for comparison. We also calculated WFI scores from published fish data for 24 sites in Green Bay, Lake Michigan (Brazner and Beals 1997).

\section{Results}

\section{Description of environmental variables}

The wetlands included in this study (Table 1) ranged from oligotrophic to hypereutrophic (Table 2) based on primary nutrient concentrations. WQI scores for each site reflect the degree of anthropogenic disturbance and the range of wetland conditions included in this study. Water depth at the open water site where water and environmental variables were collected varied between $0.2 \mathrm{~m}$ in the shallowest marshes to $4.1 \mathrm{~m}$ (mean of $1.3 \mathrm{~m}$ ). Physicochemical variables varied a great deal between sites: temperature ranged from 14.9 to $31.5^{\circ} \mathrm{C}$ (mean $23.7^{\circ} \mathrm{C}$ ), dissolved oxygen ranged from 4.4 to $13.8 \mathrm{mg} \cdot \mathrm{L}^{-1}$ (mean $8.13 \mathrm{mg} \cdot \mathrm{L}^{-1}$ ), and conductivity ranged from 91 to $1658 \mu \mathrm{S} \cdot \mathrm{cm}^{-1}$ (mean $445 \mu \mathrm{S} \cdot \mathrm{cm}^{-1}$ ) (Table 2). Chlorophyll varied between $0.5 \mu \mathrm{g} \cdot \mathrm{L}^{-1}$ for unproductive systems to $100.4 \mu \mathrm{g} \cdot \mathrm{L}^{-1}$ in eutrophic systems (mean $14.9 \mu \mathrm{g} \cdot \mathrm{L}^{-1}$ ). Water clarity, represented by suspended solids, ranged from near 0.0 to greater than $300.0 \mathrm{mg} \cdot \mathrm{L}^{-1}$. Phosphorus and nitrogen also varied a great deal between sites: $18.4-398.0 \mu \mathrm{g} \cdot \mathrm{L}^{-1}$ total phosphorus and $1.0-100.3 \mu \mathrm{g} \cdot \mathrm{L}^{-1}$ for soluble reactive phosphorus. Total ammonia had a mean of $0.09 \mathrm{mg} \cdot \mathrm{L}^{-1}$, with a range of $0.01-0.34 \mathrm{mg} \cdot \mathrm{L}^{-1}$, while total nitrate had a mean of $0.39 \mathrm{mg} \cdot \mathrm{L}^{-1}$. WQI scores ranged from -2.39 , indicative of highly degraded conditions, to 1.5 , which is indicative of very good wetland conditions (Chow-Fraser 2006); the average score was -0.23 , which is associated with moderately degraded conditions. 
Table 2. Summary of environmental conditions and in-text abbreviations encountered at 40 Great Lakes wetlands in this study.

\begin{tabular}{llll}
\hline Parameter & Mean & Median & Range \\
\hline Depth $(\mathrm{m})$ & 1.28 & 1 & $0.20-4.10$ \\
Temperature $\left(\mathrm{TEMP} ;{ }^{\circ} \mathrm{C}\right)$ & 23.7 & 24.1 & $14.8-31.5$ \\
Dissolved oxygen $\left(\mathrm{DO} ; \mathrm{mg} \cdot \mathrm{L}^{-1}\right.$ ) & 8.1 & 7.5 & $4.4-13.8$ \\
Conductivity $\left(\mathrm{COND} ; \mathrm{mS} \cdot \mathrm{cm}^{-1}\right)$ & 445 & 359 & $91-1658$ \\
Chlorophyll $a\left(\mathrm{CHLa} ; \mu \mathrm{g} \cdot \mathrm{L}^{-1}\right)$ & 14.9 & 7.1 & $0.5-100.3$ \\
Total inorganic suspended solids $\left(\mathrm{TISS} ; \mathrm{mg} \cdot \mathrm{L}^{-1}\right.$ ) & 24.4 & 5.9 & $0.3-339.0$ \\
Total organic suspended solids $\left(\mathrm{TOSS} ; \mathrm{mg} \cdot \mathrm{L}^{-1}\right)$ & 15.2 & 4.9 & $0.1-331.4$ \\
Total phosphorus $\left(\mathrm{TP} ; \mu \mathrm{g} \cdot \mathrm{L}^{-1}\right)$ & 117.8 & 97.6 & $18.4-398.0$ \\
Soluble reactive phosphorus $\left(\mathrm{SRP} ; \mu \mathrm{g} \cdot \mathrm{L}^{-1}\right)$ & 16.5 & 7 & $1.0-100.3$ \\
Total ammonia nitrogen $\left(\mathrm{TAN} ; \mathrm{mg} \cdot \mathrm{L}^{-1}\right)$ & 0.09 & 0.03 & $0.01-0.34$ \\
Total nitrate nitrogen $\left(\mathrm{TNN} ; \mathrm{mg} \cdot \mathrm{L}^{-1}\right)$ & 0.39 & 0.3 & $0.01-1.27$ \\
Water Quality Index $(\mathrm{WQI})$ & -0.23 & -0.09 & $-2.39-1.51$ \\
\hline
\end{tabular}

\section{pCCA-index development}

In total, 41 fish taxa were identified and enumerated in this study. Total number of fish caught in wetlands had a mean of 435 and a range of 34 to 4577 individuals; a majority were juveniles. Of the 15 environmental variables that were initially entered into the pCCA, five (total Kjeldahl nitrogen (TKN), total nitrogen (TN), total suspended solids (TSS), pH, and latitude) were eliminated because they were redundant (according to value of the inflation factor of $>10$ ). The final list of variables retained in the pCCA were: total phosphorus (TP), soluble reactive phosphorus (SRP), total ammonia nitrogen (TAN), total nitrate nitrogen (TNN), total inorganic suspended solids (TISS), total organic suspended solids (TOSS), chlorophyll a (CHLa), temperature (TEMP), COND, dissolved oxygen (DO), and longitude (LONG). The $U$ and $T$ values (Table 3; see Materials and methods) were assigned based on patterns that emerged from the pCCA biplot, which related the statistical mode for each species along the synthetic axes (Fig. 2). The first two environmental axes together explained $45.3 \%$ of the total variation in species $\mathrm{AB}$ data. The first axis was highly correlated with several environmental vectors, including COND $(r=0.81)$, TAN $(r=0.76)$, TP $(r=0.69)$, CHLa $(r=0.65)$, and TISS $(r=0.47)$ (Fig. 2). The second axis was highly correlated with the longitude of the wetland (LONG; $r=0.59$ ) and is likely a reflection of lake-to-lake differences in wetland development. Since similar trends were observed when PA data were used in the pCCA, the results are not presented here.

Both types of fish data (i.e., $\mathrm{AB}$ and PA) were ordinated according to their statistical mode along synthetic axis 1 . Those species (see Table 3 for key to all species codes) associated with positive values tended to be very tolerant of degraded conditions, examples of which are white perch (Morone americana; MOAM) and channel catfish (Ictalurus punctatus; ICPU), whereas species associated with negative values were intolerant of anthropogenic disturbance and tended to be more abundant in wetlands, where values for nutrients, TSS, COND, and CHLa were low, examples of which are longnose gar (Lepisosteus osseus; LEOS) and the mimic shiner (Notropis volucellus; NOVO). Although much of the variation in fish distribution was due to species-specific tolerance of habitat degradation (i.e., pCCA axis 1), some variation could be attributed to the location of wetlands (i.e., pCCA axis 2). For example, species such as johnny darter (Etheostoma nigrum; ETNI) and redfin pickerel (Esox americanus; ESAA), which were associated with the positive end of pCCA axis 2 (higher longitude), were more commonly encountered in wetlands of Lake Michigan.

The species assigned $U$ values were related to a taxon's position on the first canonical axis (Fig. 2). The freshwater drum (Aplodinotus grunniens; APGR) and goldfish (Carassius auratus; CAAU) were each given a $U$ value of 1 because their centroids were located near the positive end of axis 1 (Fig. 2), which indicates they are very tolerant of degraded conditions (Table 3). By contrast, species such as blackchin shiner (Notropis heterodon; NOHN) and the longnose gar (LEOS) were each given a $U$ value of 5 because their centroids were placed near the negative end of the pCCA axis 1, which indicates they are very intolerant of environmental degradation. All of the remaining species were assigned intermediate values $(2,3$, or 4$)$ according to the position of the species centroids along pCCA axis 1. Additional research is needed to confirm the rare species' position in the index. All species were assigned $U$ and $T$ values using the above approach and are presented separately for $\mathrm{AB}$ and PA data (Table 3).

\section{Comparison of the WFI with other indices of wetland quality}

To evaluate the ability of the WFI to characterize wetland quality, we compared them with corresponding scores of the WQI. WFI scores for the 41 wetlands were plotted against corresponding WQI scores for both the $\mathrm{PA}$ and $\mathrm{AB}$ data (Figs. $3 a$ and $3 b$, respectively). Both sets of data yielded highly significant regression equations for WFI (PA) and WFI $(\mathrm{AB})$ data $\left(r^{2}=0.64\right.$ and $r^{2}=0.59$, respectively). For comparison, we regressed conventional measures of community diversity against WQI scores. We found no significant relationship between the WQI and the Shannon-Wiener diversity index (Fig. 3c; $P=0.80$ ), the Simpson's evenness in$\operatorname{dex}$ (Fig. $3 d ; P=0.66$ ), species richness (Fig. $3 e ; P=0.11$ ), or $\log _{10}$ total abundance (Fig. $3 f ; P=0.35$ ). We also calculated scores for the Simpson's diversity index (not shown) and found no significant relationship with the WQI $(P=$ $0.84)$.

In contrast, we found a highly significant relationship between WFI scores and species richness of submersed aquatic vegetation (SAV) (Fig. 4; $r^{2}=0.70, P<0.0001$ ). WFI scores 
Table 3. Water-quality optimum $(U)$ and tolerance $(T)$ values for fish species based on presence or absence data (PA) and abundances (AB) and organized by family.

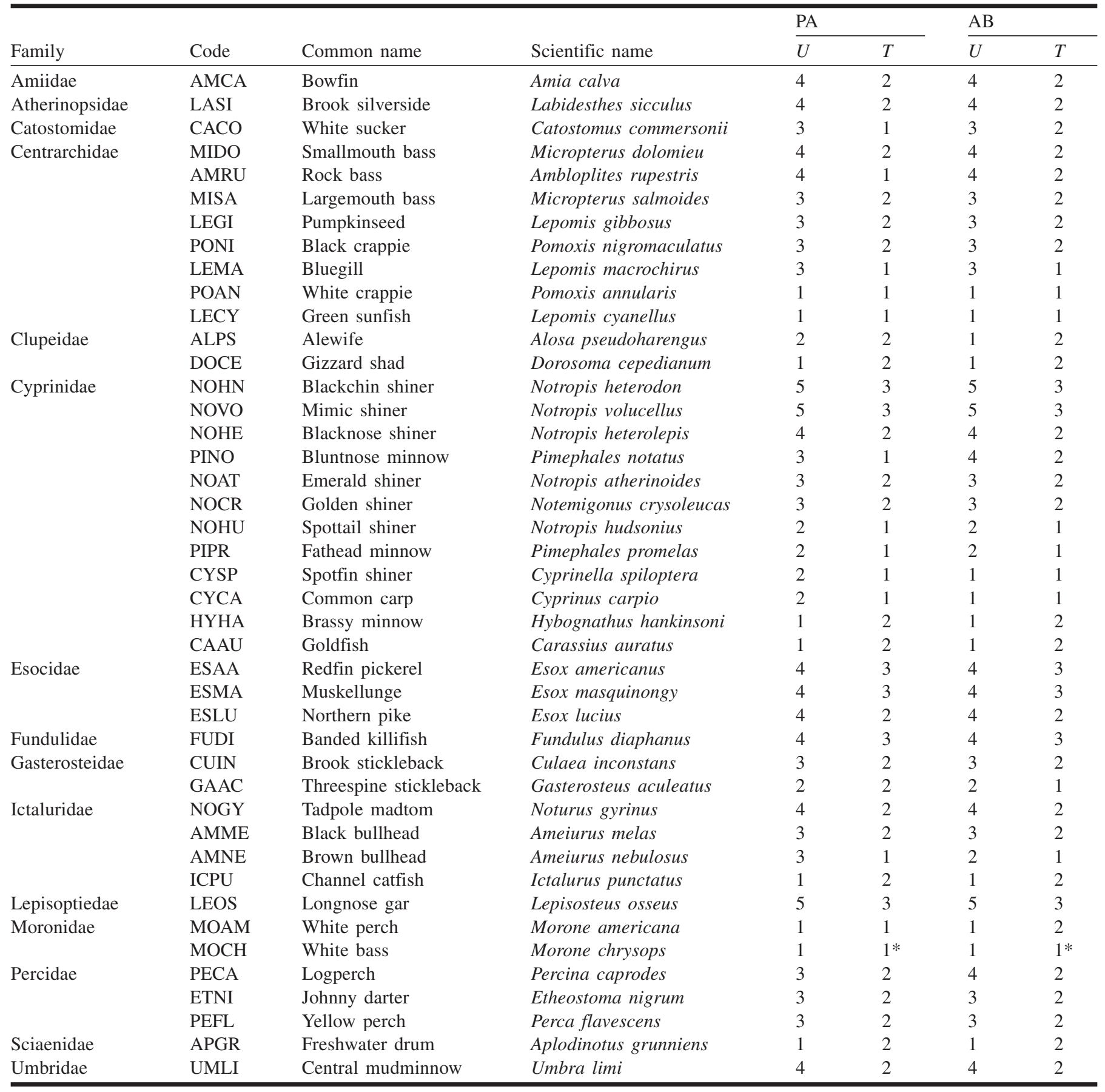

Note: $U$ values were assigned from the species' position on the first canonical axis; $T$ values were assigned based on the weighted standard deviation of the first axis species scores.

*Species occurring in $<5 \%$ of wetlands were automatically assigned a $T$ value of 1 .

increased asymptotically from less than 2.0 in wetlands that had no SAV to 3.8 when SAV richness reached 12 or greater.

Use of the WFI to assess site quality in Frenchman's Bay

The physicochemical parameters collected by the YSI probes at the two sites in Frenchman's Bay are summarized in Table 4. The probes collected hourly data for 114 days during the summer of 2002. We first calculated daily means and then compared these on a monthly basis between sites.
The ambient temperature at the North station tended to be higher than that at the South station (significantly higher in June, August, and September). Water conductivity was consistently higher at the North station, with a range of 1.171.26 times higher than that at the South station. The North station was also associated with higher water turbidity (significantly higher in June and September) and higher chlorophyll (significantly higher every month). On the other hand, there were less consistent differences with respect to dis- 
Fig. 2. Biplot of partial canonical correspondence analysis (pCCA) using $\log _{10}$ abundance data for 42 fish species on first and second canonical axes. Codes for species are shown in Table 3.

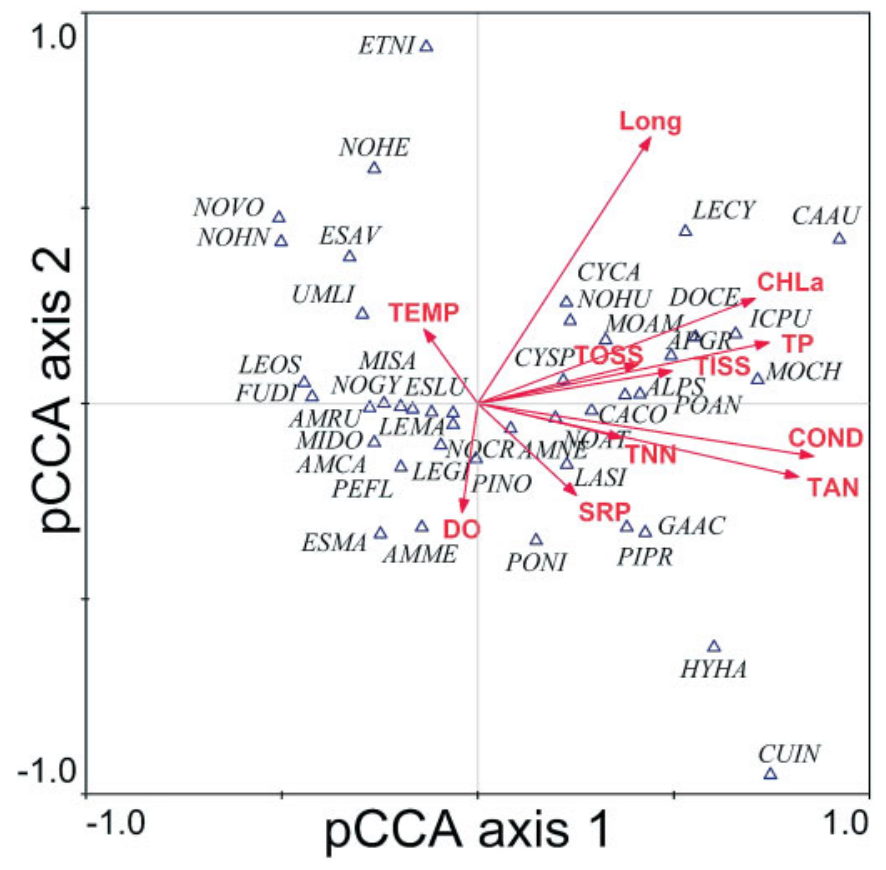

solved oxygen concentration between stations; in June, conditions were more deoxygenated in the north, whereas in September, the reverse was true, and in July and August, there were no significant differences.

The WQI scores for the two sites varied throughout the summer but the North site scores were always lower than those for the South site during 2002 (Fig. 5). Both sites also had their lowest scores at a similar time in mid- to late June, indicating that larger factors influence the Bay as a whole, even though the water quality at the South site is consistently better. For most dates, the North site was classified as moderately degraded and on a few occasions was even considered very degraded according to this index. In contrast, the South site was in the upper end of the moderately degraded category and was at times considered to be of good quality (Chow-Fraser 2006).

Differences in WFI scores between the North and South sites were consistent with differences in water-quality characteristics (Fig. 6). WFI (AB) and WFI (PA) calculated for the South station were significantly higher than those for the North (WFI (AB) 2-tailed $t$ test, $P<0.05$; WFI (PA) 1 -tailed $t$ test, $P<0.05$; 2-tailed $t$ test, $P=0.09$ ). Regardless of the type of data used, WFI scores for the South site tended to be higher than those for the North during the nine sampling occasions in 2001 and 2002 (Fig. 6). Although scores were comparable during the early part of the season, they diverged by midsummer, and by late summer, WFI scores associated with the North station were substantially lower than those associated with the South.

For comparison, we generated scores of three other published indices (Minns et al.'s (1994) Fish IBI, Wichert's (1995) WSATI-WQ, and Wichert and Lin's (1996) WSATI-WT) using fish information collected from Frenchman's Bay (Table 5). The 12 metric fish IBI scores were slightly higher for the South compared with the North site, but there were no significant differences (paired $t$ test, $P=0.44$ ). Even when we corrected for inclusion of offshore species by calculating a modified IBI* (Minns et al. 1994), we did not obtain a significant difference $(P=0.60)$. Similarly, WSATI-WQ and WSATI-WT results indicated that scores for the South site were slightly higher, but once again, we found no significant differences (paired $t$ test, $P=0.21, P=0.35$, respectively).

\section{Validation of the WFI}

The fish information from Brazner and Beals (1997) was used to generate WFI (AB) and WFI (PA) scores for each of the 24 sites in Green Bay. The WFI (PA) and WFI (AB) were equally effective for showing regional differences among sites; scores were lowest in the lower bay, increased in the middle bay, and were highest in the upper bay (Table 6). Scores of WFI (PA) increased significantly from the lower bay (2.36) to middle bay (2.79) to upper bay (3.07) (analysis of variance (ANOVA); Tukey-Kramer; $P<0.05)$. Similarly, mean scores for the WFI (AB) showed a significant increase from 2.18 in the lower bay to 2.65 in the middle bay and to 3.04 in the upper bay $(P<0.05$; Table 6$)$. Neither of the WFI scores could distinguish between wetland and beach habitats (2.70 vs. 2.79 for WFI (PA); 2.54 vs. 2.70 for WFI $(\mathrm{AB}))$ when the data were pooled; however, when site types were re-analyzed by region, we found significant $(P<0.01)$ differences between beach and wetland habitats within each portion of Green Bay (2.27 vs. 2.46, 2.77 vs. 2.81, and 3.05 vs. 3.10 for lower, middle, and upper Green Bay, respectively). Overall, beach habitat in the lower bay was associated with the lowest scores (2.27 and 2.12 for WFI (PA) and WFI (AB), respectively), while wetland habitat in the upper bay had the highest scores (3.10 and 3.12 for WFI (PA) and WFI (AB), respectively). By contrast, there were no significant differences between developed and undeveloped sites when regional differences were ignored (2.70 vs. 2.76 for WFI (PA), $P=0.89 ; 2.63$ vs. 2.61 for WFI (AB), $P=0.67)$. These results are consistent with Brazner and Beals' (1997) conclusions that both site-specific environmental characteristics and information from ordinations and cluster analysis of the fish assemblages varied among the three major regions, with habitats in the less urbanized upper Green Bay having the best quality, those in the heavily urbanized and industrialized lower bay being the most degraded, and those in the moderately impacted middle bay having intermediate quality. They also concluded that the differences in fish assemblages between beach and wetland habitats were likely the result of reduced macrophyte cover due to increased wave exposure in the former.

\section{Discussion}

The WFI was developed based on quantifiable relationships between fish distribution and associated water quality conditions for 40 coastal wetlands located primarily in the lower Great Lakes. Based on WQI scores calculated for these sites, wetlands in this study included sites that were highly degraded because of nutrient and sediment enrichment, as well as high-quality sites that were relatively undisturbed by human activities. When compared with other diversity indices such as Shannon-Wiener's H', Simpson's 
Fig. 3. (a) Wetland Fish Index (WFI) calculated with presence or absence (PA) fish data $\left(r^{2}=0.64, P<0.0001\right)$, $(b)$ WFI calculated with $\log _{10}$ abundance $(\mathrm{AB})$ fish data $\left(r^{2}=0.59, P<0.0001\right),(c)$ Shannon-Wiener's $\mathrm{H}^{\prime}(P=0.80)$, $(d)$ Simpson's evenness $(P=0.65)$, (e) species richness $\left(r^{2}=0.08, P=0.11\right)$, and $(f) \log _{10}$ abundance $(P=0.35)$ versus corresponding Water Quality Index (WQI) scores for 41 Great Lake coastal wetlands.
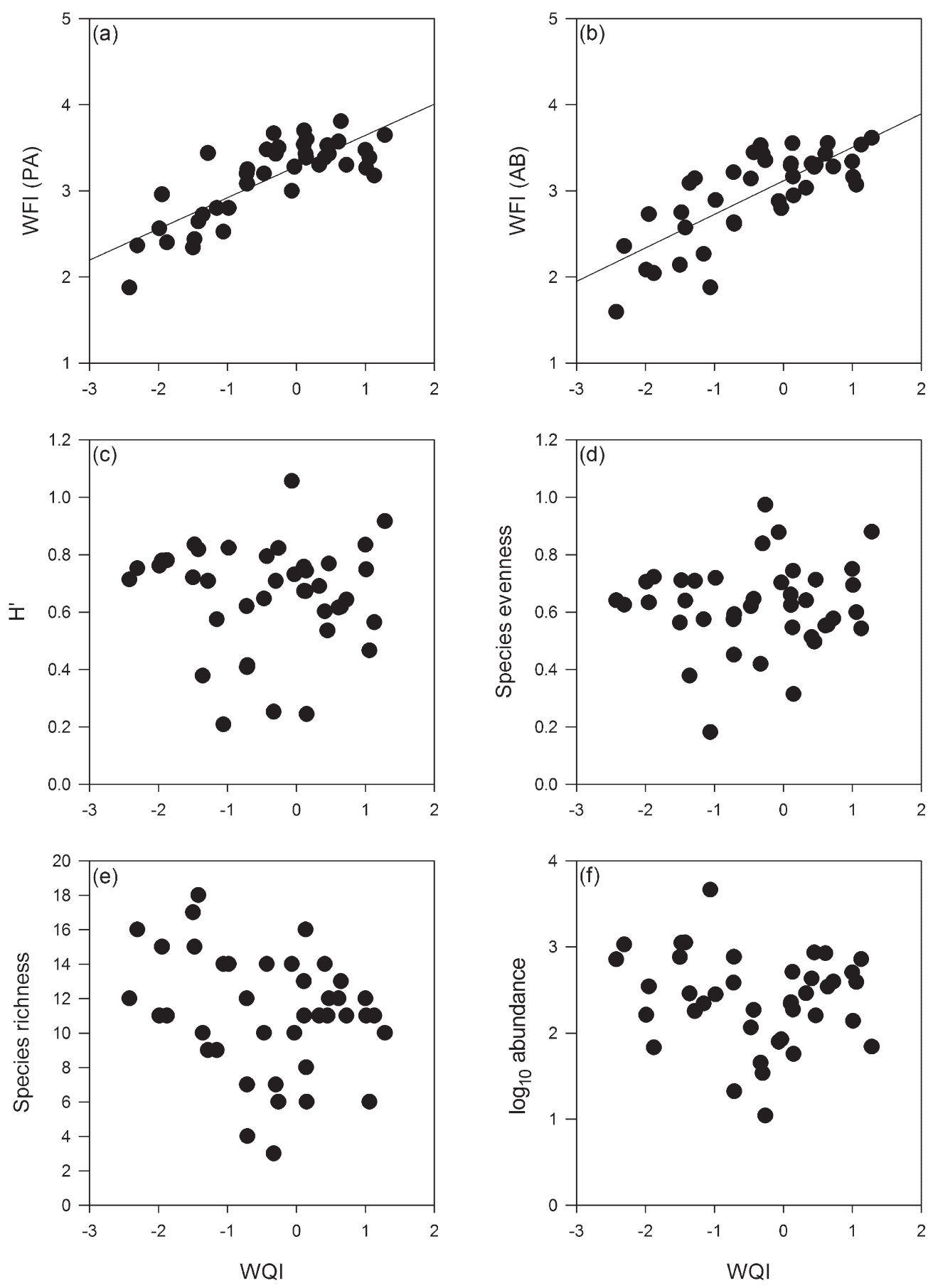

evenness, and species richness, only the WFI (calculated with either the $\mathrm{PA}$ or $\mathrm{AB}$ data) varied as a linear function of WQI, demonstrating that the WFI is more useful than the others as an indicator of anthropogenic impact. Species diversity and richness are probably less sensitive to degradation in this case, because turnover in the fish community resulting from habitat degradation does not necessarily lead to changes in species diversity or richness (e.g., Chow-Fraser

et al. 1998). As well, a large number of tolerant species could result in a higher diversity score for degraded sites, and this may explain why species richness was negatively correlated with WQI score. Species-specific tolerances based on observed trends in wetlands were more informative than diversity and richness alone. Additional factors such as metal contamination and recreational usage may also affect the fish community, but we have only focused on the im- 
Fig. 4. Relationship between Wetland Fish Index presence or absence (WFI (PA)) scores and the species richness of submersed aquatic vegetation. Data are fitted with a quadratic regression analysis $\left(r^{2}=0.70, P<0.0001\right)$.

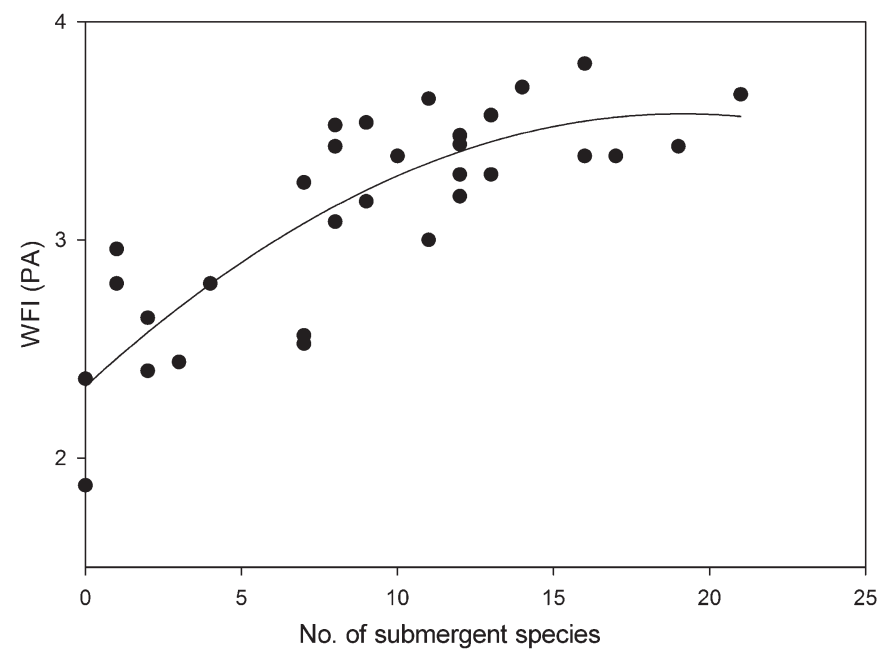

pacts related to nutrients, turbidity, and conductivity. This could limit the usefulness of the WFI in situations where other stressors are contributing to changes in the fish community. Use of the WFI may also be limited to coastal wetlands in the Great Lakes region and should not be directly applied to smaller inland lakes without validation.

That wetland degradation leads to changes in the fish community has already been documented for wetlands such as Cootes Paradise Marsh (Chow-Fraser et al. 1998) and Green Bay (Brazner 1997) and forms a scientifically defensible basis for formulation of the WFI. Deterioration in water quality reduces plant diversity and biomass (Lougheed et al. 2001), and this can affect fish negatively in two ways. First, it is widely accepted that juvenile fish use macrophytes to hide from piscivores (Scott and Crossman 1998). Second, macrophytes provide shelter for plankton and benthic invertebrates, which are essential prey items for both juvenile fish and benthivores (Jude and Pappas 1992). Increased water turbidity can also affect the acuity of visual feeders and make it more difficult for them to forage. Once the habitat becomes degraded, exotic invaders such as common carp assert their dominance, promoting higher turbidity and causing further deterioration in the macrophyte community (Chow-Fraser 1999). The WFI is effective in linking this species shift across the trophic gradient, from fish assemblages that are intolerant of pollution in unimpacted wetlands with abundant SAV to fish that are very tolerant of pollution in degraded wetlands with very little or no SAV. The relationship between WFI and water quality is in part an indirect consequence of the strong relationship between desirable fish species, which are weighted highly by the WFI, and the species richness of SAV, which is directly regulated by water quality and turbidity (Lougheed et al. 2001).

Although the $U$ and $T$ values assigned to the species were based on statistical relationships between fish occurrence and water quality, they are also consistent with what is known about the ecology of the species. For instance, the longnose gar (LEOS) and blackchin shiner (NOHN) are identified as highly intolerant of degradation $(U=5)$. The longnose gar depends heavily on aquatic vegetation throughout its life cycle (Scott and Crossman 1998). The blackchin shiner prefers cool, clear waters and quickly disappears when turbidity increases and the amount of submerged vegetation decreases (Trautman 1981). By comparison, we classified both pumpkinseed (Lepomis gibbosus; LEGI) and brown bullhead (Ameiurus nebulosus; AMNE) as moderately tolerant of degradation $(U=3)$. The fact that both species were distributed widely within our database (present in over 60\% of the wetlands) fits with the conventional wisdom that these species can spawn in a variety of habitat types, but prefer moderate vegetation (Scott and Crossman 1998). In contrast, white perch (Morone americana; MOAM) have been found in eutrophic areas of Lake Champlain, where there is elevated turbidity and chlorophyll (Hawes and Parrish 2003; these documented observations support our assigning these latter species a low $U$ value of 1 .

One advantage of the WFI over the WZI and WQI is that it can provide more rapid assessments. Although more specialized and sometimes expensive equipment is required to assess the fish community, virtually all the data can be processed immediately in the field with moderate training. By comparison, both the zooplankton and water-quality samples require specialized equipment, as well as lab processing, analyses, and technical expertise that can add months to the assessment process. Karr (1991) found that fish assessment was less costly than chemical-physical water quality and other bioassays, but was only slightly less expensive than macroinvertebrate community assessment. Fish are only one of many bioindicators in use today, but it is only a single tool and should be used in accord with other indices for greatest knowledge of wetland condition.

The use of PA or AB data in calculating the WFI produced very similar results for both the sites we sampled and those in Green Bay. An advantage of the WFI (PA) over WFI (AB) is that the PA index may be used with historic species lists that do not have accompanying fish abundances. The WFI (PA) may also be relatively stable through the season, since a few spawning adults and many juveniles will lead to the same score, and therefore restrictions on time of sampling may be relaxed. Chow-Fraser et al. (2006) consistently caught more fish with fyke nets than with boat electrofishing across a large gradient of wetland quality. Where different sampling gears are involved in fish collection, the data may have to be standardized prior to application of the WFI (AB). Comparison of WFI scores should be restricted to sites where similar fishing methods are used because this will reduce the effects of gear selectivity if the bias for all sites is kept constant. When abundance is used to calculate the WFI, the nature of the formula allows for a larger range of scores, especially when there is a large number of the indicator species (i.e., $U=1$ or 5 ).

We have demonstrated two uses for the WFI in this paper. First, we demonstrated the usefulness of the WFI for detecting intrawetland variation between two sites with different water-quality characteristics in a small, urbanized wetland (Frenchman's Bay, Lake Ontario). We showed that wetland quality at the North station was more degraded than that at the South station, as indicated by significantly higher CHLa, 
Table 4. Comparison of environmental variables between North and South sites in Frenchman's Bay.

\begin{tabular}{|c|c|c|c|c|c|}
\hline \multirow[b]{2}{*}{ Variable } & \multirow[b]{2}{*}{ Month } & \multicolumn{2}{|l|}{ South } & \multicolumn{2}{|l|}{ North } \\
\hline & & Mean & SE & Mean & SE \\
\hline \multirow[t]{4}{*}{ Temperature $\left({ }^{\circ} \mathrm{C}\right)$} & June & 18.9 & 0.54 & 20.5 & 0.58 \\
\hline & July & 23.4 & 0.29 & 25.8 & 0.28 \\
\hline & August & 23.5 & 0.31 & 24.5 & 0.37 \\
\hline & September & 21.1 & 0.41 & 24.4 & 0.47 \\
\hline \multirow[t]{4}{*}{ Dissolved oxygen $\left(\mathrm{mg} \cdot \mathrm{L}^{-1}\right)$} & June & 9.83 & 0.30 & 7.15 & 0.39 \\
\hline & July & 8.40 & 0.17 & 6.04 & 1.00 \\
\hline & August & 9.44 & 0.20 & 9.51 & 0.15 \\
\hline & September & 7.26 & 0.16 & 8.34 & 0.33 \\
\hline \multirow[t]{4}{*}{ Conductivity $\left(\mu \mathrm{S} \cdot \mathrm{cm}^{-1}\right)$} & June & 371 & 4.2 & 461 & 5.1 \\
\hline & July & 354 & 1.6 & 424 & 10.5 \\
\hline & August & 332 & 5.4 & 390 & 6.3 \\
\hline & September & 352 & 1.1 & 446 & 16.6 \\
\hline \multirow[t]{4}{*}{ Turbidity (NTU)* } & June & 12.2 & 3.08 & 36.7 & 5.45 \\
\hline & July & 6.7 & 0.65 & 11.9 & 4.01 \\
\hline & August & 4.1 & 0.52 & 4.6 & 1.36 \\
\hline & September & 5.5 & 0.97 & 18.5 & 3.98 \\
\hline \multirow[t]{4}{*}{ Chlorophyll $a\left(\mu \mathrm{g} \cdot \mathrm{L}^{-1}\right)$} & June & 25 & 1.6 & 30 & 1.5 \\
\hline & July & 13 & 0.5 & 21 & 2.0 \\
\hline & August & 10 & 0.5 & 18 & 0.9 \\
\hline & September & 12 & 0.7 & 16 & 0.9 \\
\hline
\end{tabular}

Note: Means of all parameters were compared with paired $t$ tests (Bonferroni-corrected $\alpha=0.05$ ). For each pair that was significantly different $(P<0.05)$, the larger number appears in bold. SE, standard error.

*Nephelometric turbidity units.

Fig. 5. Comparison of Water Quality Index (WQI) scores for North (solid squares) and South (open squares) sites in Frenchman's Bay, Lake Ontario, during 2002.

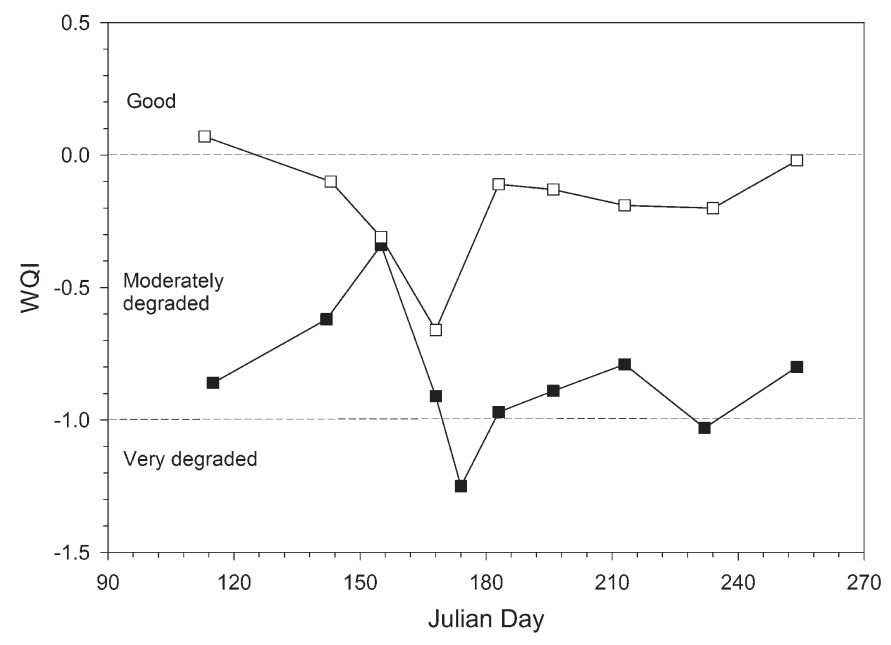

conductivity, and turbidity and lower WQI scores; and lower species diversity of SAV (McNair and Chow-Fraser 2003). The WFI was sufficiently sensitive to separate the two sites based only on fish assemblage data. Although other indices showed a trend towards higher scores in the South site, none were significant. The WFI was able to significantly detect differences between the North and South sites, probably because it had been developed with a large gradient of wetlands in three Great Lakes. The other indices had been developed for a relatively narrow range of wetland types (IBI; Great Lakes AOC) or areas (WSATI; Toronto streams) and had not been developed specifically for coastal marshes. Both the WFI (AB) and WFI (PA) were effective in identifying the more degraded quality of the North station, although the WFI (PA) scores were more consistent compared with corresponding WFI (AB) values. This suggests that PA data may be less susceptible to either regional or seasonal differences in fish distribution. This shows that the WFI is an effective indicator of wetland quality and can be used to compare sites within a wetland during a monitoring program or to gauge the impacts of wetland development or restoration over time. Second, we have generated WFI scores for a historic data set from an area of the Great Lakes that had not been included in the development of the index. The WFI successfully differentiated among three regions in Green Bay (Brazner and Beals 1997) in terms of overall habitat quality for wetland-associated fish species. The fact that three different gears (fyke nets, seines, and minnow traps) had been used to collect the fish did not appear to affect the ability of the WFI to discriminate among habitat quality, as long as fishing effort had been consistent. However, additional research is needed to determine if WFI scores generated solely by one gear type can be used interchangeably with those generated solely by another gear type (e.g., electrofishing boat versus paired fyke nets). Fish-based indices are only a single tool that can be used for assessing wetland condition, and while they can produce rapid assessments, they should be used in association with other metrics and trophic levels for a complete understanding of the stresses on the system. Nevertheless, the Wetland Fish Index should prove to be an effective tool to aid in the management and protection of important fish habitat in coastal wetlands of the Laurentian Great Lakes. 
Fig. 6. Comparison of Wetland Fish Index (WFI) (a) presence or absence (PA) and $(b)$ abundance (AB) scores for North (solid squares) and South (open squares) sites in Frenchman's Bay, Lake Ontario, during 2002.
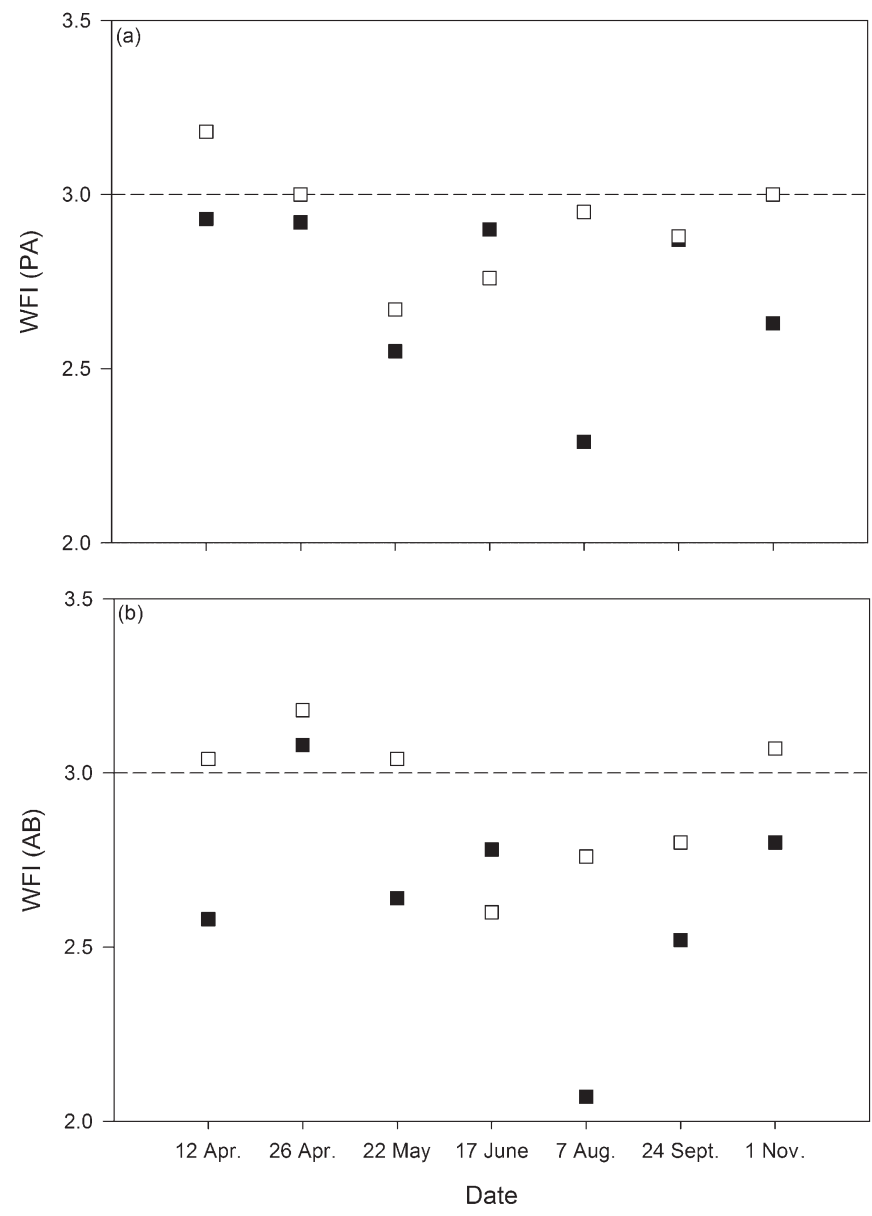

Table 5. Comparison of Wetland Fish Index (WFI) for presence or absence (PA) and abundance (AB), Index of Biotic Integrity (IBI; Minns et al. 1994), and Weighted Species-Association Tolerance Index for Water Quality (WSATI-WQ) and Water Temperature (WSATI-WT; Wichert and Lin 1996) calculated for 7 separate days in 2002.

\begin{tabular}{lrlrrl}
\hline & \multicolumn{2}{c}{ North } & & \multicolumn{2}{c}{ South } \\
\cline { 2 - 3 } & Mean & SE & & Mean & SE \\
\hline WFI (PA)* & 2.73 & 0.09 & & 2.92 & 0.06 \\
WFI (AB)** & 2.64 & 0.12 & & 2.93 & 0.08 \\
IBI & 53.78 & 5.66 & 60.31 & 6.39 \\
WSATI-WQ & 5.60 & 0.60 & 6.68 & 0.64 \\
WSATI-WT & 20.69 & 1.48 & & 22.88 & 1.55 \\
\hline
\end{tabular}

Note: Asterisks denote significant differences between sites $(*, 1$-tailed paired $t$ test $P<0.05 ; * *, 2$-tailed paired $t$ test $P<0.05$ ). SE, standard error.

\section{Acknowledgements}

We greatly appreciate the financial support of the Great Lakes Fishery Commission in the form of a Fishery Research Grant to PC-F and a Norman S. Baldwin Fishery Science Scholarship to TSS. Support from Ontario Innovation
Table 6. Wetland Fish Index (WFI) scores (PA, presence or absence species data used; $\mathrm{AB}, \log _{10}$ abundance species data used) calculated for wetlands and beaches in Green Bay, Lake Michigan, based on fish surveys conducted by Brazner (1997).

\begin{tabular}{|c|c|c|c|c|c|}
\hline & \multirow[b]{2}{*}{$N$} & \multicolumn{2}{|c|}{ WFI (PA) } & \multicolumn{2}{|c|}{ WFI (AB) } \\
\hline & & Mean & SE & Mean & SE \\
\hline \multicolumn{6}{|l|}{ Region } \\
\hline Lower & 4 & $2.36 \mathrm{a}$ & 0.06 & $2.18 \mathrm{a}$ & 0.06 \\
\hline Middle & 4 & $2.79 \mathrm{~b}$ & 0.04 & $2.65 b$ & 0.06 \\
\hline Upper & 4 & $3.07 \mathrm{c}$ & 0.03 & $3.04 \mathrm{c}$ & 0.09 \\
\hline \multicolumn{6}{|l|}{ Habitat site type } \\
\hline Beach & 12 & $2.70 \mathrm{a}$ & 0.10 & $2.54 \mathrm{a}$ & 0.11 \\
\hline Wetland & 12 & $2.79 \mathrm{a}$ & 0.09 & $2.70 \mathrm{a}$ & 0.12 \\
\hline \multicolumn{6}{|c|}{ Region and site type } \\
\hline Lower, beach & 2 & $2.27 \mathrm{a}$ & 0.04 & $2.12 \mathrm{a}$ & 0.04 \\
\hline Lower, wetland & 2 & $2.46 a b$ & 0.11 & $2.23 \mathrm{ab}$ & 0.11 \\
\hline Middle, beach & 2 & $2.77 \mathrm{ab}$ & 0.06 & $2.55 \mathrm{ab}$ & 0.07 \\
\hline Middle, wetland & 2 & $2.81 \mathrm{~b}$ & 0.05 & $2.75 b c$ & 0.08 \\
\hline Upper, beach & 2 & $3.05 \mathrm{c}$ & 0.03 & $2.94 \mathrm{c}$ & 0.14 \\
\hline Upper, wetland & 2 & $3.10 \mathrm{c}$ & 0.05 & $3.12 \mathrm{c}$ & 0.10 \\
\hline \multicolumn{6}{|l|}{ Development type } \\
\hline Developed & 12 & $2.72 \mathrm{a}$ & 0.10 & $2.63 \mathrm{a}$ & 0.12 \\
\hline Undeveloped & 12 & $2.76 \mathrm{a}$ & 0.09 & $2.61 \mathrm{a}$ & 0.12 \\
\hline
\end{tabular}

Note: Means with the same letter indicate they are not significantly different $(P>0.05)$ as indicated by a Tukey-Kramer post hoc test.

Trust and University of Toronto (Nick Eyles) through funds to purchase continuous monitoring equipment at Frenchman's Bay is also appreciated. Some of the fish surveys were carried out by research partners: M. Weimer at the US Fish and Wildlife Service in Amherst, New York; D. Albert and T. Burton at Michigan State University, East Lansing, Michigan; D. Tanner and J. Brazner at the US Environmental Protection Agency Lab in Duluth, Minnesota; and T. MacDougall of the Ontario Ministry of Natural Resources, Port Dover, Ontario. We thank J. Brazner for providing valuable suggestions for improvements on previous versions of this manuscript. We also acknowledge the tremendous contributions of a great team of graduate and undergraduate students who assisted in the field and laboratory throughout the project, especially S. McNair, B. Reich, M. Strack, and K. Kostuk.

\section{References}

Bailey, R.G. 1995. Description of the ecoregions of the United States. USDA Forest Service, Ft. Collins, Colo. Available from http:// www.fs.fed.us/institute/ecoregions/ecoreg1_home.html [accessed 1 October 2004; updated 17 August 2001].

Brazner, J.C. 1997. Regional, habitat, and development influences on coastal wetland and beach fish assemblages in Green Bay, Lake Michigan. J. Gt. Lakes Res. 23: 36-51.

Brazner, J.C., and Beals, E.W. 1997. Patterns in fish assemblage from coastal wetland and beach habitats in Green Bay, Lake Michigan: a multivariate analysis of abiotic and biotic forcing factors. Can. J. Fish. Aquat. Sci. 54: 1743-1761.

Casselman, J.M., and Lewis, C.A. 1996. Habitat requirements of northern pike (Esox lucius). Can. J. Fish. Aquat. Sci. 53(Suppl. 1): $161-174$. 
Chow-Fraser, P. 1999. Seasonal, interannual and spatial variability in the concentrations of total suspended solids in a degraded coastal wetland of L. Ontario. J. Gt. Lakes Res. 25: 799-813.

Chow-Fraser, P. 2006. Development of the Wetland Water Quality Index (WQI) to assess effects of basin-wide land-use alteration on coastal marshes of the Laurentian Great Lakes. In Coastal wetlands of the Laurentian Great Lakes: health, habitat and indicators. Chapter 5. Edited by T.P. Simon and P.M. Stewart. Indiana Biological Survey, Bloomington, Indiana. In press.

Chow-Fraser, P., and Albert, D. 1998. Identification of "ecoreaches" of Great Lakes coastal wetlands that have high biodiversity value. In Proceedings for the Third State of the Lakes Ecosystem Conference (SOLEC '98), 21-23 October 1998, Buffalo, N.Y. Environment Canada, Ottawa, Ont., and US Environmental Protection Agency, Washington, D.C. pp. 1-102.

Chow-Fraser, P., Lougheed, V.L., Crosbie, B., LeThiec, V., Simser, L., and Lord, J. 1998. Long-term response of the biotic community to fluctuating water levels and changes in water quality in Cootes Paradise Marsh, a degraded coastal wetland of Lake Ontario. Wetlands Ecol. Manag. 6: 19-42.

Chow-Fraser, P., Kostuk, K., Seilheimer, T., Weimer, M., MacDougall, T., and Theÿsmeÿer, T. 2006. Effect of wetland quality on sampling bias associated with two fish survey methods for coastal wetlands of the lower Great Lakes. In Coastal wetlands of the Laurentian Great Lakes: health, habitat and indicators. Chapter 10. Edited by T.P. Simon and P.M. Stewart. Indiana Biological Survey, Bloomington, Indiana. In press.

Crosbie, B., and Chow-Fraser, P. 1999. Percentage land use in the watershed determines the water and sediment quality of 22 marshes in the Great Lakes basin. Can. J. Fish. Aquat. Sci. 56: 1781-1791.

Environment Canada. 2001. Durham region coastal wetland monitoring project proposal and background report. Canadian Wildlife Service, Downsview, Ont.

Eyles, N., Doughty, M., Boyce, J.I., Meriano, M., and Chow-Fraser, P. 2003. Geophysical and sedimentological assessment of urban impacts in a Lake Ontario watershed and lagoon: Frenchman's Bay, Pickering, Ontario. Geosci. Can. 30: 115-128.

Fuller, K., Shear, H., and Wittig, J. (Editors). 1995. The Great Lakes: an environmental atlas and resource book. Environment Canada, Ottawa, Ont., and United States Environmental Protection Agency, Chicago, Ill.

Hawes, E.J., and Parrish, D.L. 2003. Using abiotic and biotic factors to predict the range expansion of white perch in Lake Champlain. J. Gt. Lakes Res. 29: 268-279.

Jude, D.J., and Pappas, J. 1992. Fish utilization of Great Lakes coastal wetlands. J. Gt. Lakes Res. 18: 651-672.

Karr, J.R. 1981. Assessment of biotic integrity using fish communities. Fisheries, 6:21-27.

Karr, J.R. 1991. Biological integrity: a long-neglected aspect of water resource management. Ecol. Appl. 1: 66-84.
Kelly, M.G., and Whitton, B.A. 1995. The trophic diatom index: a new index for monitoring eutrophication in rivers. J. Appl. Phycol. 7: 433-444.

Lougheed, V.L., and Chow-Fraser, P. 2002. Development and use of a zooplankton index of wetland quality in the Laurentian Great Lakes basin. Ecol. Appl. 12: 474-486

Lougheed, V.L., Crosbie, B., and Chow-Fraser, P. 1998. Predictions of the effect of carp exclusion on water quality, zooplankton, and submergent macrophytes in a Great Lakes wetland. Can. J. Fish. Aquat. Sci. 55: 1189-1197.

Lougheed, V.L., Crosbie, B., and Chow-Fraser, P. 2001. Primary determinants of macrophyte community structure in 62 marshes across the Great Lakes basin: latitude, land use, and water quality effects. Can. J. Fish. Aquat. Sci. 58: 1603-1612.

McNair, S.A., and Chow-Fraser, P. 2003. Change in biomass of benthic and planktonic algae along a disturbance gradient for 24 Great Lakes coastal wetlands. Can. J. Fish. Aquat. Sci. 60: 676-689.

Minns, C.K., Cairns, V.W., Randall, R.G., and Moore, J.E. 1994. An index of biotic integrity (IBI) for fish assemblages in the littoral zone of Great Lakes' Areas of Concern. Can. J. Fish. Aquat. Sci. 51: 1804-1822.

Scott, W.B., and Crossman, E.J. 1998. Freshwater fishes of Canada. 2nd ed. Bull. Fish. Res. Board Can. No. 184.

ter Braak, C.J.F., and Smilauer, P. 1998. CANOCO reference manual and user's guide to CANOCO for windows: software for canonical community ordination. Version 4. Microcomputer Power, Ithaca, N.Y.

ter Braak, C.J.F., and Verdonschot, P.F.M. 1995. Canonical correspondence analysis and related multivariate methods in aquatic ecology. Aquat. Sci. 57: 255-289.

Trautman, M.B. 1981. The fishes of Ohio with illustrated keys. Revised edition. Ohio State University Press, Colombus, Ohio.

Wei, A., Chow-Fraser, P., and Albert, D. 2004. Influence of shoreline features on fish distribution in the Laurentian Great Lakes. Can. J. Fish. Aquat. Sci. 61: 1113-1123.

Weigel, B.M. 2003. Development of stream macroinvertebrate models that predict watershed and local stressors in Wisconsin. J. North Am. Benthol. Soc. 22: 123-142.

Wichert, G.A. 1995. Effects of improved sewage effluent management and urbanization on fish associations of Toronto streams. N. Am. J. Fish. Manag. 15: 440-456.

Wichert, G.A., and Lin, P. 1996. A species tolerance index for maximum water temperature. Water Qual. Res. J. Can. 31: 875-893.

Wilcox, D.A., Meeker, J.E., Hudson, P.L., Armitage, B.J., Black, MG., and Uzarski, D.G. 2002. Hydrologic variability and the application of index of biotic integrity metrics to wetlands: a Great Lakes evaluation. Wetlands, 22: 588-615. 